\title{
Childhood obesity and parental health literacy
}

\begin{abstract}
Recent data have indicated that having a high body mass index poses immense health risks to children, and adolescents. This review describes the recent research on childhood obesity-an epidemic of global proportions- and parental health literacy. Based on the available information, it provides guidelines for public health professionals interested in preventing or reducing overweight in youth and obesity in adults. To this end, English language peer reviewed publications and data reporting on the topics of overweight, obesity and health literacy were reviewed to specifically examine the interrelationship of these factors. Findings reveal childhood obesity is an ongoing widespread health concern, where intervening to prevent the onset of obesity should start in the formative years. It is concluded that such strategies should be grounded upon fostering accurate parental perceptions about the condition, as well as efforts to help parents with low health literacy to detect and intervene upon this condition.
\end{abstract}

Volume 3 Issue 3 - 2015

\author{
Ray Marks ${ }^{1,2}$ \\ 'Department of Health \& Behavioral Sciences, City University of \\ New York, USA \\ ${ }^{2}$ Department of Health and Behavior Studies, Columbia \\ University, USA

\begin{abstract}
Correspondence: Ray Marks, Department of Health \& Behavioral Sciences, City University of New York, and Department of Health and Behavior Studies, Teachers College, Columbia University, New York, NY, USA, Tel 2126783445.
\end{abstract} \\ Email rmarks@york.cuny.edu,rm226@columbia.edu
}

Received: July 29, 2015 | Published: October 14, 2015

Keywords: childhood obesity, health literacy, parents, perceptions, prevention

\section{Introduction}

Childhood overweight is an unrelenting public health challenge that shows few signs of abating. ${ }^{1-5}$ Moreover, regardless of where the research is conducted, additional research shows many preventable diseases are associated with the early onset of obesity, and this risk increases incrementally as the magnitude of an individual's obesity level increases. Nonetheless, given that current campaigns designed to minimize this burdensome public health have made very little major impact to date, it appears important to continue to examine what else needs to be done to combat this problem.

One emerging body of promising research shows that parents, who have great influence over their children's health practices may repeatedly misperceive either the importance of childhood overweight or the presence of childhood overweight or both. Another body of literature shows that being health literate is an important element of health related behaviors that may be undermining public health attempts to ameliorate childhood obesity, especially among groups with low levels of educational attainment.

This brief examines the concept of health literacy, the possible role of health literacy in mediating overweight problems in children, and how this knowledge might be applied to enhance present preventive efforts. Also included in this review are recent data stressing the importance of fostering accurate parental perceptions as well as knowledge about their children's actual body weight status, as well as their vulnerability to becoming overweight and its detrimental long term outcomes. All types of research was deemed acceptable as this line of research is in its infancy. The results of the search strategy used when applying the key terms health literacy and childhood obesity is shown in Table 1. Other data published between 2014 and 2015 that discussed parental weight perceptions in the context of childhood obesity were sought, carefully read, and summarized (Table 2).

Table I Number of resources available on topic 2000-20I5

\begin{tabular}{lll}
\hline Data base & Number of references & Number of appropriate references \\
\hline Cinahl & 3 & 1 \\
PUBMED & 35 & 5 \\
Scopus & 51 & 5 \\
Web of Science & 40 & 6 \\
\hline
\end{tabular}

Table 2 Publications on topic of childhood obesity and parental perceptions

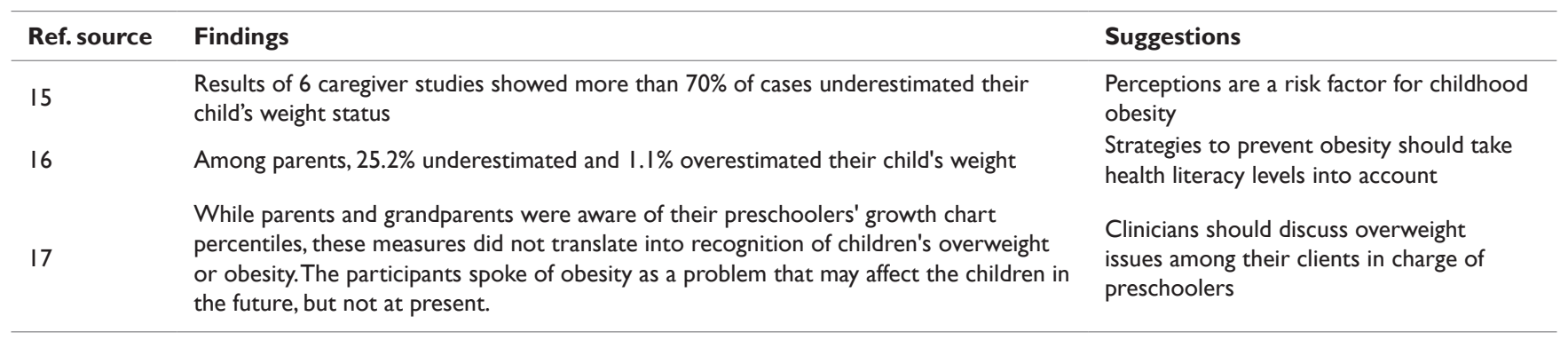


Table Continued....

\begin{tabular}{|c|c|c|}
\hline Ref. source & Findings & Suggestions \\
\hline 18 & $\begin{array}{l}\text { Parents of } 3-12 \text { year olds reported inaccurate height and weight data, or underestimated } \\
\text { degree overweight }\end{array}$ & $\begin{array}{l}\text { Parents need to be able to report weight } \\
\text { issues accurately where present. }\end{array}$ \\
\hline 19 & Most participants found growth charts and the term "BMI" confusing. & $\begin{array}{l}\text { Linking body weight and its health } \\
\text { association is valuable for motivating } \\
\text { parents with overweight kids towards } \\
\text { action }\end{array}$ \\
\hline 20 & $\begin{array}{l}\text { Overweight or obese parents and parents of boys were more likely to underestimate } \\
\text { the actual weight status of their children. }\end{array}$ & $\begin{array}{l}\text { Obesity underestimation is a possible risk } \\
\text { factor for childhood obesity }\end{array}$ \\
\hline 21 & $\begin{array}{l}\text { The majority }(79.8 \%) \text { of preschoolers who were classified as overweight using BMI } \\
\text { percentile were perceived as non-overweight by the parent in the first } 2 \text { years-of-life. }\end{array}$ & $\begin{array}{l}\text { Parent weight perceptions in the first } \\
2 \text { years of life may heighten risk for obesity/ } \\
\text { overweight }+ \text { unhealthy diets that can be } \\
\text { modified }\end{array}$ \\
\hline 22 & $\begin{array}{l}\text { There is a major discrepancy between the child's measured BMI and their parent's } \\
\text { perception of their child's weight category. }\end{array}$ & $\begin{array}{l}\text { Managing children's weight should start } \\
\text { with education of parents }\end{array}$ \\
\hline
\end{tabular}

\section{Results}

\section{Health literacy}

Derived from the field of education, the term 'health literacy,' has been deemed by researchers in the field to represent literacy skills related to vocabulary, materials, and directives employed in health care settings. ${ }^{6}$ Health numeracy, defined as those "skills needed to understand quantitative health information" " is another important component within the realm of health literacy and one found lacking in a substantive proportion of adults worldwide, ${ }^{8}$ especially among those with low incomes and low educational levels. Since adults with either limited literacy, or limited numeracy skills or both are likely to have limited ability to carry out desirable health practices, and may be completely unaware of the need to do so, they may have a strong negative influence on others under their care. They may not only be unaware of the risks of their guardians, but may hold beliefs that are not borne out by facts, they may also not understand facts, or messages needed to prevent adverse health outcomes.

Huizinga et al., ${ }^{9}$ recount that in 2003, the National Assessment of Adult Literacy (NAAL) found that approximately 90million Americans have basic or below basic literacy skills and that 110 million have basic or poor quantitative (numeracy) skills. These findings were independently associated with having a poor understanding of health information, poor health behaviors, and poor clinical outcomes. In the context of nutrition and obesity, low health literacy/numeracy was associated with worse knowledge about breastfeeding, difficulty understanding food labels and portion sizes and higher body mass index (BMI) in adults. This group recounts that Surgeon General Richard Carmona not only acknowledged that health literacy was a major problem in the United States, but that he recognized that low health literacy was potentially a strong explanatory factor related to the proliferating obesity problem.

A more recent cross-sectional study by Yin et al., ${ }^{10}$ did indeed find eleven percent of parents of 2-month old children had low health literacy. In addition, low parental health literacy was associated with certain obesogenic infant care behaviors. The findings included reports of parents feeding their children more formula than breast milk if they were low health literate, they fed their child as soon as it cried. The authors suggested these behaviors and others may serve as modifiable targets for low health literacy-focused interventions to help reduce childhood obesity.
Garret ${ }^{11}$ who reported results from logistic regression analyses demonstrated that the parent's health literacy level was a significant predictor of the accuracy of their perceptions regarding their child's body weight $(\mathrm{p}<.05)$. However, the parent's concern regarding child weight and perceived level of efficacy did not significantly predict the accuracy of their perceptions. Content analyses revealed that parents are often uncertain how to define healthy or unhealthy body weights in children. Parents in the study often relied on subjective observations to determine the appropriateness of child body weight, but many were open to counseling and education from medical professionals, Internet resources, and other objective sources.

Chari et al., ${ }^{12}$ conducted an anonymous survey among English speaking parents. They found the odds for obesity in children increased with low health literacy scores of the parents. Cha et al., ${ }^{13}$ too who found obesogenic infant care behaviours may increase childhood obesity, and predict obesity and related health risks in adulthood reported poor parental health literacy predicted poor child health outcomes, including childhood obesity.

Cluss et al., ${ }^{14}$ measured nutrition knowledge of parents of Medicaidinsured obese children using a simple health literacy tool. Although health literacy was not specifically examined, this group found the parents' understanding of food's nutritional value is variable, and those who were black, had less education, and very low income had poorer nutrition knowledge than others with better education.

One reason why poor health literacy may impact childhood obesity rates is the impact of poor understanding of a health issue on the caregiver's perceptions of related health risks. Unsurprisingly Tomlkins et al., ${ }^{15}$ who conducted a 2006-2012 systematic review-and found an underestimation of obesity ranging from 13.3 to $100 \%$ of parents of overweight children found parental health literacy was one of the factors that affected accuracy of parental perceptions. Related findings are shown in Table 2 and show the consistent misinterpretation of childhood obesity by caregivers.

\section{Discussion}

Despite the limited number of research articles on this topic, parental health literacy is clearly a significant factor that can contribute inadvertently to the obesity epidemic, as well as its solutions. As outlined by Huizing et al., ${ }^{9}$ who discussed the prevention of early childhood obesity, interventions to foster health literacy concerning 
childhood obesity and its causes and solutions among parents might be extremely helpful in this regard, given the link between the extent of this skill and accuracy of their child's weight perception. ${ }^{11}$ In particular, tailored efforts that target the parent or caregiver's comprehension and application levels, plus their numeracy skill level are potentially helpful. In addition, the material should be culturally relevant. For example, information for Latino parents and their children should contain information about healthy food choices from commonly consumed food from their culture. Parents also need practical tools that they can use to aid in the interpretation of food labels and in meal planning. They also need aids to understand the proper caloric intake and body composition of small children.

White et al., ${ }^{23}$ who reported on the Growing Right Onto Wellness (GROW) trial, a childhood obesity prevention study targeting a low health literate population stated the modules for this curriculum are appropriate for persons with low health literacy. Promotion of health literacy in general in the public may further benefit efforts to minimize the childhood obesity epidemic, ${ }^{24}$ as many parents may tend to be unaware of their child's overweight problem. ${ }^{18}$

Sanders et al. ${ }^{25}$ noted children who become overweight by age 2 years have significantly greater risks of long-term health problems, and children in low-income communities, where rates of low adult literacy are highest, are at increased risk of developing obesity and that health literacy may be a critical modifiable factor for reducing child health problems, and others among this group. The Greenlight Intervention Study to assess the effectiveness of a low-literacy, primary-care intervention on the reduction of early childhood obesity may be helpful in this respect.

Velardo \& Drummond ${ }^{26}$ stated that health literacy, which relates to the acquisition, understanding and application of health information, has become an increasingly important public health issue, particularly where parents and children are concerned, and must be assessed and intervened upon accordingly at the earliest point in time. Cha et al., ${ }^{13}$ further stated nurses should routinely assess parent health literacy and provide appropriate support to prevent obesogenic infant care behaviors. The same approach by other providers is strongly indicated as well. Future research in this realm would undoubtedly be helpful, as might work to evaluate parent educational programs tailored to health literacy level and effectiveness on reducing obesogenic care behaviors.

Since overweight children are also more likely to become obese adults, and are at greater risk for adult health problems than those who are of normal weight, the role of low health literate parents in reducing this risk should receive more attention. As was observed by the small number of related publications on this topic, the overlap between parental misperceptions, and childhood obesity, and health literacy warrants more attention, especially if parents with inaccurate perceptions of their child's health status are likely to ignore appropriate health messages as discussed by Aljunaibi et al..$^{27}$ It seems reasonable to assume that increased obesity-related knowledge, may translate into heightened motivation to make family changes related to body weight and health, ${ }^{28}$ while distorted maternal parental perception leads to excess weight being perceived as normal. ${ }^{29}$ Being a young mother and having a daughter may raise the risk of underestimation. ${ }^{30}$ Hence preventive programs should include effort to increase the mother's or caregiver's weight status perception. ${ }^{30}$ Jones $^{31}$ who found parents misidentified if their children were overweight or obese, found parents did not understand, use or trust clinical measures, thus often remaining detached from the issue. They stressed the importance of improving parental recognition of childhood overweight as well as engagement in its management. As reiterated by Chaperro ${ }^{32}$ if parents fail to recognize their overweight child is overweight, they will be less inclined to recognize the importance of applying targeted obesity programs to their family. Wen \& Hui ${ }^{33}$ concluded that the accurate classification of children's weights by parents could help prevent childhood obesity. However, lack of education and role modeling ${ }^{34}$ are barriers to prevention that need to be overcome.

Parents may specifically not realize:

a. Soft drinks can be as dangerous and habit forming as cigarettes;

b. Getting children to move is as important as their cognitive development; and

c. Teaching them to respect about how media usage and viewing influences obesity risks is important.

They may also not realize that their own behaviors can be noticed and readily modeled, and that they can influence better health choices through their own actions in the community, and home settings. They themselves might therefore benefit from some form of education in this regard.

Parents can also help youth to develop life skills, skills for making effective judgments and choices, as well as offering supportive and safe environments that make the healthier choice the easier choice. If given the opportunity, children can learn about what creates health. What are the most important health determinants of chronic noncommunicable diseases and how to practice positive health behaviors at all times. Sleep patterns, which can favor the onset of obesity inadvertently, can be mediated by parents, and should be optimized, and regulated, and efforts to improve parent's overall health literacy may be highly fruitful, especially if parents do not understand, use or trust clinical measures of overweight, but alternative approaches that rely on extreme cases ${ }^{31}$ and commonly underestimate weight of overweight or obese children as outlined by Regber et al. in a study of eight countries in Europe ${ }^{35}$ and Musaad et al., ${ }^{36}$ in an American based study where $93 \%$ were not perceived as overweight or obese by the parent. Despite limitations to this study and others, more research using well designed controlled prospective trials among different target groups is clearly indicated given the compelling data that has emerged to date.

\section{Conclusion}

The current findings suggest that health literacy is a potentially unrecognized obesity determinant due to its impact on parental views about child weight loss strategies and health information-seeking preferences, as well as health knowledge, in general. Leighty et al., ${ }^{37}$ have consequently suggested that pediatric weight loss advice to parents should include both an assessment of parent attitudes, as well as their knowledge about child weight control and that they should help parents to access reliable sources of child weight control information. Garrett-Wright ${ }^{38}$ who studied perceptions of parents among preschoolers in the context of obesity, indicated that assessing parental perceptions of preschool children's body weight could help providers to better comprehend how parents view their children and could thus lead to more efficient suitably tailored educational interventions in the future. In addition, they suggested parental health literacy might hold the key to providing high-quality family-centered care. Providing such care is imperative as indicated by a recent expose in the New York Times that showed a considerable lack of parental 
understanding about childhood overweight issues. ${ }^{39}$ Approaches that should be tested in future work might include some of the above mentioned ideas, plus efforts by parents to counteract the unhealthy influence of television on diet, including nutrition education, media literacy education to teach children to defend against unwanted influence; and reduced exposure to unhealthy messages. ${ }^{40}$ Basic research that examines the correlates examined in this brief and the importance of providing parents with cogent information and skills should also be examined.

\section{Acknowledgements}

None.

\section{Conflict of interest}

The author declares no conflict of interest.

\section{References}

1. Department of Health. Obesity as a major public health threat. USA New York; 2014.

2. Centers for Disease Control and Prevention. Body Mass Index. 2014.

3. Harvard School of Public Health. Obesity trends. 2014.

4. Centers for Disease Control and Prevention. Trends in the prevalence of extreme obesity among US preschool-aged children living in lowincome families, 1998-2010. JAMA. 2012;308(24):2563-2565.

5. Clinical Guidelines on the Identification, Evaluation and Treatment of Overweight and Obesity in Adults: The Evidence Report. National Heart Lung and Blood Institute; 2014. 228 p.

6. Rudd RE, Moeykens BA, Colton TC. Health and Literacy: A Review of Medical and Public Health Literature. USA: New York; 1999.

7. Ancker JS, Kaufman D. Rethinking health numeracy: A multidisciplinary literature review. J Am Med Inform Assoc. 2007;14(6):713-721.

8. Smith SG, Wolf MS, von Wagner C. Socioeconomic status, statistical confidence and patient-provider communication: An analysis of the Health Information National Trends Survey (HINTS 2007). J Health Comm. 2010;15(Suppl 3):169-185.

9. Huizinga MM, Pont S, Rothman RL, et al. ABC's and 123's: Parental Literacy, Numeracy and Childhood Obesity. Obes Manag. 2008;4(3):98103.

10. Yin HS, Sanders LM, Rothman RL, et al. Parent health literacy and "obesogenic" feeding and physical activity-related infant care behaviors. J Pediatr. 2014;164(3):577-583.

11. Garrett D. Parental Perceptions of Overweight in Toddlers and Preschool Children [e-book]. England: Vanderbilt University, CINAHL; 2008.

12. Chari R, Warsh J, Ketterer T, et al. Association between health literacy and child and adolescent obesity. Patient Educ Couns. 2014;94(1):61-66.

13. Cha E, Besse JL. Low parent health literacy is associated with 'obesogenic' infant care behaviours. Evid Based Nurs. 2015;18(2):46.

14. Cluss PA, Ewing L, King WC, et al. Nutrition knowledge of low-income parents of obese children. Transl Behav Med. 2013;3(2):218-225.

15. Tompkins CL, Seablom M, Brock DW. Parental perception of child's body weight: a systematic review. J Child and Fam Studies. 2015;24:1384-1391.

16. Chen HY, Lemon SC, Pagoto SL, et al. Personal and parental weight misperception and self-reported attempted weight loss in US children and adolescents, National Health and Nutrition Examination Survey, 2007-2008 and 2009-2010. Prev Chronic Dis. 2014;11:140132.
17. Eli K, Howell K, Fisher PA, et al. "A little on the heavy side": a qualitative analysis of parents' and grandparents' perceptions of preschoolers' body weights. BMJ Open. 2014;4(12):e006609.

18. Gordon NP, Mellor RG. Accuracy of parent-reported information for estimating prevalence of overweight and obesity in race-ethnically pediatric clinic population aged 3-12. Pediatr. 2015;15:5.

19. Knierim SD, Rahm AK, Haemer M, et al. Latino parents' perceptions of weight terminology used in pediatric weight counseling. Acad Pediatr. 2015;15(2):210-217.

20. Manios Y, Moschonis G, Karatzi K, et al. Large proportions of overweight and obese children, as well as their parents, underestimate children's weight status across Europe. The ENERGY (EuropeaN Energy balance Research to prevent excessive weight Gain among Youth) project. Public Health Nutr. 2015;18(12):2183-2190.

21. Musaad SM, Donovan SM, Fiese BH, et al. Parental perception of child weight in the first two years-of-life: a potential link between infant feeding and preschoolers' diet. Appetite. 2015;91:90-100.

22. Spargo M, Mellis C. Childhood obesity and parental perceptions in a rural Australian population: a pilot study. J Paediatr Child Health. 2014;50(2):131-134.

23. White RO, Thompson JR, Rothman RL, et al. A health literate approach to the prevention of childhood overweight and obesity. Patient Educ Couns. 2013;93(3):612-618.

24. Feng A, Wang L, Chen X, et al. Developmental origins of health and disease (DOHaD): Implications for health and nutritional issues among rural children in China. Biosci Trends. 2015;9(2):82-87.

25. Sanders LM, Perrin EM, Yin HS, et al. "Greenlight study":a controlled trial of low-literacy, early childhood obesity prevention. Pediatrics. 2014;133(6):e1724-e1737.

26. Velardo S, Drummond M. Understanding parental health literacy and food related parenting practices. Hlth Sociol Rev. 2013;22(2):137-150.

27. Aljunaibi A, Abdulle A, Nagelkerke N. Parental weight perceptions: a cause for concern in the prevention and management of childhood obesity in the United Arab Emirates. PLoS One. 2013;8(3):e59923.

28. Mareno N. Parental perception of child weight: a concept analysis. $J A d v$ Nurs. 2014;70(1):34-45.

29. Camargo AP, Barros Filho Ade A, Antonio MÂ, et al. [The non perception of obesity can be an obstacle to the role of mothers in taking care of their children]. Cien Saude Colet. 2013;18(2):323-333.

30. Souto-Gallardo MC, Jiménez-Cruz A, Bacardí-Gascón M. Parents perception of weight status of Mexican preschool children using different tools. Arch Latinoam Nutr. 2011;61(4):382-388.

31. Jones AR, Parkinson KN, Drewett RF, et al. Parental perceptions of weight status in children: the Gateshead Millennium Study. Int J Obes. 2011;35(7):953-962.

32. Chaparro MP, Langellier BA, Kim LP, et al. Predictors of accurate maternal perception of their preschool child's weight status among Hispanic WIC participants. Obesity. 2011;19(10):2026-2030.

33. Wen X, Hui SS. Chinese parents' perceptions of their children's weights and their relationship to parenting behaviours. Child Care Health Dev. 2011;37(3):343-351.

34. Sosa ET. Mexican American mothers' perceptions of childhood obesity: a theory-guided systematic literature review. Health Educ Behav. 2012;39(4):396-404.

35. Regber S, Novak M, Eiben G, et al. Parental perceptions of and concerns about child's body weight in eight European countries - the IDEFICS study. Pediatr Obes. 2013;8(2):118-129. 
36. Musaad SM, Paige KN, Teran-Garcia M, et al. Childhood overweight obesity and pediatric asthma: the role of parental perception of child weight status. Nutrients. 2013;5(9):3713-3729.

37. Liechty JM, Saltzman JA, Musaad SM. Health literacy and paren attitudes about weight control for children. Appetite. 2015;91:200-208.

38. Garrett-Wright D. Parental perception of preschool child body weight. $J$ Pediatr Nurs. 2011;26(5):435-445.
39. Hughes D. Parents not recognising obesity in their own children. 2015.

40. Harris JL, Bargh JA. Television viewing and unhealthy diet: implications for children and media interventions. Health Commun. 2009;24(7):660 673. 